\title{
Efficacy of Combined Therapy with Cyclosporin and Low-Dose Prednisolone in Interstitial Pneumonia Associated with Connective Tissue Disease
}

\author{
Naohiro Watanabe ${ }^{a}$ Koji Sakamoto ${ }^{a}$ Hiroyuki Taniguchi $^{b}$ Yasuhiro Kondoh ${ }^{b}$

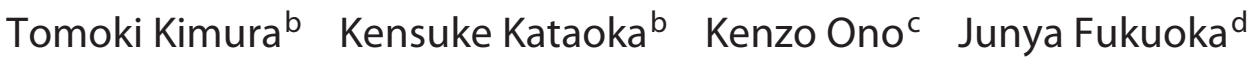 \\ Osamu Nishiyama ${ }^{\mathrm{e}}$ Yoshinori Hasegawa ${ }^{\mathrm{a}}$ \\ ${ }^{a}$ Department of Respiratory Medicine, Nagoya University Graduate School of Medicine, Nagoya, Departments of \\ ${ }^{\mathrm{b}}$ Respiratory Medicine and Allergy and ${ }^{\mathrm{C} P a t h o l o g y, ~ T o s e i ~ G e n e r a l ~ H o s p i t a l, ~ S e t o, ~}{ }^{\mathrm{d}}$ Department of Pathology, Nagasaki \\ University Graduate School of Biomedical Sciences, Nagasaki University, Nagasaki, and e Department of Respiratory \\ Medicine and Allergology, Kinki University Faculty of Medicine, Osakasayama, Japan
}

\section{Key Words \\ Connective tissue diseases · Cyclosporin · Interstitial pneumonia $\cdot$ Prednisolone}

\begin{abstract}
Background: The optimal treatment method for interstitial pneumonia (IP) with connective tissue disease (CTD) remains controversial. In addition, a clinically meaningful end point to judge drug efficacy has not been fully investigated. Objectives: The aim of this study was to evaluate, from various aspects, the therapeutic benefit and tolerability of combined therapy with cyclosporin A (CsA) and low-dose prednisolone (PSL) for chronic fibrosing CTD-IP patients. Methods: A total of 26 CTD-IP patients diagnosed by surgical lung biopsy and subsequently treated with the above combination therapy were retrospectively reviewed. The therapeutic regimen comprised methylprednisolone induction therapy for 2-4 weeks, followed by a combined therapy of CsA with low-dose PSL for 1 year. Evaluation of the therapeutic benefit was based on not only pulmonary function but also exercise capacity, health-related quality of life and dyspnea. Results: After 1 year of therapy, clinically significant improvements in forced vital capacity $(\geq 10 \%)$, carbon monox-
\end{abstract}

ide diffusing capacity of the lung ( $\geq 15 \%)$, 6-min walk distance ( $\geq 28 \mathrm{~m}$ ), and St. George's Respiratory Questionnaire $(\leq-7)$ were observed in $61.5,69.2,61.5$ and $69.2 \%$ of the patients, respectively. All measurements showed statistically significant improvements compared with baseline values. The 1-year treatment did not need to be discontinued in any patients due to unacceptable toxicity, and no deaths occurred. Conclusions: Combined therapy with CSA and lowdose PSL for CTD-IP patients was well-tolerated and patients displayed a noteworthy response.

๑) 2014 S. Karger AG, Basel

\section{Introduction}

Connective tissue disease (CTD) constitutes a group of systemic autoimmune disorders including rheumatoid arthritis (RA), systemic sclerosis (SSc), Sjögren syndrome (SjS), polymyositis/dermatomyositis (PM/DM), mixed connective tissue disease (MCTD) and systemic lupus erythematosus (SLE). Interstitial pneumonia (IP) is fre-

N. Watanabe and K. Sakamoto contributed equally to this study.

\section{KARGER}

E-Mail karger@karger.com

www.karger.com/res
C 2014 S. Karger AG, Basel

0025-7931/14/0876-0469\$39.50/0
H. Taniguchi

Department of Respiratory Medicine and Allergy

Tosei General Hospital, 160 Nishioiwake-cho

Seto, Aichi 489-8642 (Japan)

E-Mail taniguchi@ tosei.or.jp 
quently observed in patients with CTD, and it remains a leading cause of death $[1,2]$.

In daily practice, corticosteroids and immunosuppressive agents are regarded as the mainstay of therapy for CTD-IP. However, the optimal treatment method for CTD-IP patients remains controversial because there have been only a few small studies on this besides some which included only patients with SSc-related IP (SSc-IP) [3-10].

Cyclosporin A (CsA) inhibits the activation of T cells by uniting with calcineurin, which plays an important role in the cell signaling of T cell activation. Findings from several studies have suggested that $\mathrm{T}$ cells may play an essential role in the pathogenic mechanism of CTD-IP and could thus be therapeutic targets [11-13]. CsA has also been reported to be effective for CTD-IP, although the number of reports is extremely limited [6-9]. CsA also has a competitive inhibitory effect on P-glycoprotein 1 , which is reported to be one of the mechanisms of resistance to corticosteroids in CTD patients [14]. Combined therapy with CsA and low-dose prednisolone (PSL) is thus considered promising in CTD-IP patients.

Recently, exercise capacity and patient-reported outcomes including dyspnea and health-related quality of life (HRQoL) have come to play an increasing role in measuring the therapeutic response along with mortality and the physiological parameters for idiopathic pulmonary fibrosis patients $[15,16]$. On the other hand, few trials have evaluated such outcomes in CTD-IP patients, and thus their significance is not well known $[4,5]$.

In order to evaluate the efficacy and tolerability of a combined therapy of CsA and low-dose PSL, we retrospectively reviewed a series of CTD-IP patients who underwent 1 year of this treatment. To assess the different aspects of the effects of the treatment, the changes in pulmonary function, exercise capacity, HRQoL and the severity of dyspnea were simultaneously assessed.

\section{Materials and Methods}

\section{Patient Selection}

The institutional records of patients with chronic fibrosing IP, i.e. usual interstitial pneumonia (UIP) or fibrosing nonspecific IP (f-NSIP) diagnosed by surgical lung biopsy and subsequently treated with CsA and low-dose PSL were retrospectively collected and analyzed. Between January 2003 and December 2011, a total of 297 patients with interstitial lung disease were diagnosed by surgical lung biopsy at the Tosei General Hospital (Aichi, Japan), and a total of 48 were diagnosed as having CTD-IP. Among them, 36 patients had UIP or f-NSIP. Seven had not received any drug treatment, 2 had insufficient follow-up data and 1 who had respiratory failure at initial presentation could not be evaluated for all end points. These patients were therefore excluded from our analysis. The remaining 26 patients comprised the study cohort; they were treated with CsA and low-dose PSL as described below. The decision to initiate treatment was based on consideration of the symptoms and clinical course of each patient at meetings in our hospital, with disagreements being resolved by consensus. The study was approved by the Ethics Committee of the Tosei General Hospital.

\section{Diagnosis of Chronic Fibrosing IP and CTD}

All available lung biopsy specimens were reviewed by 2 experienced pulmonary pathologists (K.O. and J.F.) and these were classified using the histopathological patterns described in the American Thoracic Society/European Respiratory Society international consensus classification of idiopathic IPs [17]. Patients classified as having CTD met prespecified criteria according to the American College of Rheumatology criteria for diagnosis of the following conditions: RA, SSc, SjS, PM/DM and MCTD [18-22].

\section{Treatment Methods}

Patients received methylprednisolone (mPSL) induction therapy for 2-4 weeks, followed by a combined therapy of gelatin capsules of CsA (Neoral) with PSL $20 \mathrm{mg}$ on alternate days for 1 year. The mPSL induction therapy was as follows: $2-4$ cycles of intravenous drip of mPSL 1,000 mg/day for 3 days/week or intravenous drip of $\mathrm{mPSL} 2 \mathrm{mg} / \mathrm{kg} /$ day for 2 weeks, $1 \mathrm{mg} / \mathrm{kg} /$ day for the next week and $0.5 \mathrm{mg} / \mathrm{kg} /$ day for the week after that. Since large doses of corticosteroids are thought to be more effective than conventional doses, high-dose induction therapy was used for the first phase of treatment [23]. The initial dose of CsA prescribed was $3 \mathrm{mg} / \mathrm{kg}$ daily and the level of CsA in the blood was monitored monthly to facilitate adjustment of the dose. We attempted to keep the blood trough level of CsA between 100 and $150 \mathrm{ng} / \mathrm{ml}$ throughout the course of treatment. Immunosuppressive agents originally taken for the treatment of CTD were interrupted at the start of the MPSL induction therapy. All patients received prophylactic therapy with trimethoprim-sulfamethoxazole (TMP-SMX) in one tablet (TMP $80 \mathrm{mg} / \mathrm{SMX} 400 \mathrm{mg}$ ) orally per day from the start of the 1-year therapy.

\section{Assessment Approaches}

We performed the following measurements in addition to spirometry and the lung's diffusing capacity for carbon monoxide (DLco) just prior to treatment (within 1 month), and after 1 year of combination therapy. The changes in forced vital capacity (FVC) and DLco were assessed 2-3 months before the therapy, after 1 month of treatment (immediately following 4 weeks of combination therapy) and after 1 year of combination therapy. Spirometry and DLco (both CHESTAC-55V; Chest, Tokyo, Japan) were measured according to the American Thoracic Society/ European Respiratory Society recommendations as physiological assessments $[24,25]$. The results of pulmonary function tests are expressed as percentages of the normal predicted values. Exercise capacity was measured by a 6-min walk test (6MWT) [26] and the St. George's Respiratory Questionnaire (SGRQ) was used to assess HRQoL [27]. The SGRQ score included three component scores (symptom, activity and impact) and a total score [27]. Each component of the SGRQ score can range from 0 to 100, with a lower score denoting a better HRQoL. The modified Medical Research Council (mMRC) scale was used to assess the severity of dyspnea [28]. The mMRC score system ranges from 0 to 4 points, with higher points showing greater dyspnea. 
Significant Improvement Level of Each Variable

In this study, we defined clinically significant improvement/ deterioration of each variable as follows, based on previous reports regarding idiopathic pulmonary fibrosis: $\geq 10 \%$ improvement/ deterioration in $\mathrm{FVC}$ and $\geq 15 \%$ improvement/deterioration in DLco [29]. For the 6-min walking distance (6MWD) and SGRQ score, the minimal clinically important difference was estimated from previous reports and this was utilized as the threshold: $28 \mathrm{~m}$ improvement/deterioration in $6 \mathrm{MWD}$ and $\geq 7$ point decrease/ increase in total SGRG score [30, 31].

\section{Monitoring of Adverse Events}

All clinical and laboratory data were collected retrospectively from medical records. A physical examination was performed every day during the MPSL induction phase (2-4 weeks) and at least once a month thereafter. At each monthly follow-up visit, we evaluated the patients for any adverse effects of therapy and measured blood pressure, complete blood count and renal and liver biochemistry. Renal dysfunction was defined as a serum creatinine level of $>141 \mu \mathrm{mol} / \mathrm{l}$ and increased blood pressure was defined as an increase of $>25 \mathrm{~mm} \mathrm{Hg}$ in systolic pressure or $>12 \mathrm{~mm} \mathrm{Hg}$ in diastolic pressure [32].

\section{Survival Status}

Survival status as of May 2013 was established from clinical records.

\section{Statistical Analysis}

Data are presented as counts or median with ranges or mean \pm $\mathrm{SD}$. The Friedman test, a nonparametric equivalent of the repeated-measures analysis of variance, was used to spot any change in pulmonary function at the different moments of testing. For those variables showing significant differences, post hoc analysis with the Scheffe test was conducted. Differences in the other measurement values for each variable (6MWD, SGRQ and mMRC) before and after 1 year of therapy were evaluated using the Wilcoxon signed-rank test. For 2-group comparisons involving categorical variables, we used the $\chi^{2}$ test or the Fisher exact test. Changes in the total score of SGRQ and changes in the pulmonary function test, 6MWD and mMRC were correlated using the Spearman nonparametric analysis. $\mathrm{p}<0.05$ was considered significant.

\section{Results}

\section{Baseline Patient Characteristics}

The baseline characteristics of the 26 consecutive patients are summarized in table 1 . Before being diagnosed with IP, 7 patients had received treatment for CTD: 2 with PSL $5 \mathrm{mg} /$ day and an immunosuppressive agent (cyclophosphamide:mizoribine 1:1), 2 with PSL $5 \mathrm{mg} /$ day and an antirheumatic drug (methotrexate:bucillamine 1: 1) and 3 with salazosulfapyridine. No patients had received supplemental oxygen.

All patients had had histopathological confirmation of fibrosing IP by surgical lung biopsy, recorded as UIP $(\mathrm{n}=$
Table 1. Characteristics of all patients

\begin{tabular}{llc}
\hline Male/female & & $7 / 19$ \\
Age, years & & $59.0(38-74)$ \\
CTD & RA & 11 \\
& SSc & 4 \\
& PM/DM & 7 \\
& SjS & 2 \\
& MCTD & 1 \\
& RA/SjS & 1 \\
Histopathologic diagnosis & UIP & 7 \\
& f-NSIP & 19 \\
\hline
\end{tabular}

Data are shown as median (range) or number.

${ }^{\text {a }}$ One case was an overlap syndrome of RA and $\mathrm{SjS}$.

7) or f-NSIP ( $n=19)$. The CTD type of those with the histopathological UIP pattern was RA in 6 and PM/DM in 1. The CTD type of those with the f-NSIP pattern was $\mathrm{RA}$ in 5, SSc in 4, PM/DM in 6, SjS in 2, MCTD in 1 and $\mathrm{RA} / \mathrm{SjS}$ in 1 . Physiological data at baseline and the changes over 1 year are summarized in table 2 . FVC was normal ( $>80 \%$ of the predicted value) in 10 patients, while DLco was $>80 \%$ of predicted in all patients at baseline.

\section{Treatment Efficacy}

In the 2-3 months preceding the year of combined therapy, there was a statistically significant deterioration in both FVC and DLco (FVC: $\mathrm{p}=0.0052$ and DLco: $\mathrm{p}=$ 0.0361; fig. 1). After 1 month on the treatment, a statistically significant improvement was observed in FVC compared to that at baseline ( $2.02 \pm 0.63$ vs. $2.22 \pm 0.64$ liters, $\mathrm{p}=0.0045)$. DLco did not show a statistically significant improvement $(8.58 \pm 2.96$ vs. $9.40 \pm 3.14 \mathrm{ml} / \mathrm{min} /$ Torr, $\mathrm{p}=0.2296$ ). Clinically significant improvements in FVC and DLco were observed in $16(61.5 \%)$ and 9 patients (34.6\%) after 1 month, respectively. After 1 year of therapy, both had improved statistically significantly compared with baseline values (FVC: $2.02 \pm 0.63$ vs. $2.42 \pm$ 0.73 liters, $\mathrm{p}<0.0001$; DLco: $8.58 \pm 2.96$ vs. $10.59 \pm 4.02$ $\mathrm{ml} / \mathrm{min} /$ Torr, $\mathrm{p}=0.0004)$. Clinically significant improvements in FVC and DLco were observed in 16 (61.5\%) and 18 patients (69.2\%) after 1 year of therapy, respectively (table 3). FVC of predicted value increased from 71.3 to $89.6 \%$. Between 1 month and 1 year, there were significant differences in both FVC and DLco (FVC: $\mathrm{p}=0.0061$ and DLco: $p=0.0487$ ), with clinically significant improvements being observed in $12(46.2 \%)$ and 13 patients (50.0\%), respectively. There were statistically significant differences in FVC and DLco over time (FVC: $\mathrm{p}=0.0003$ 


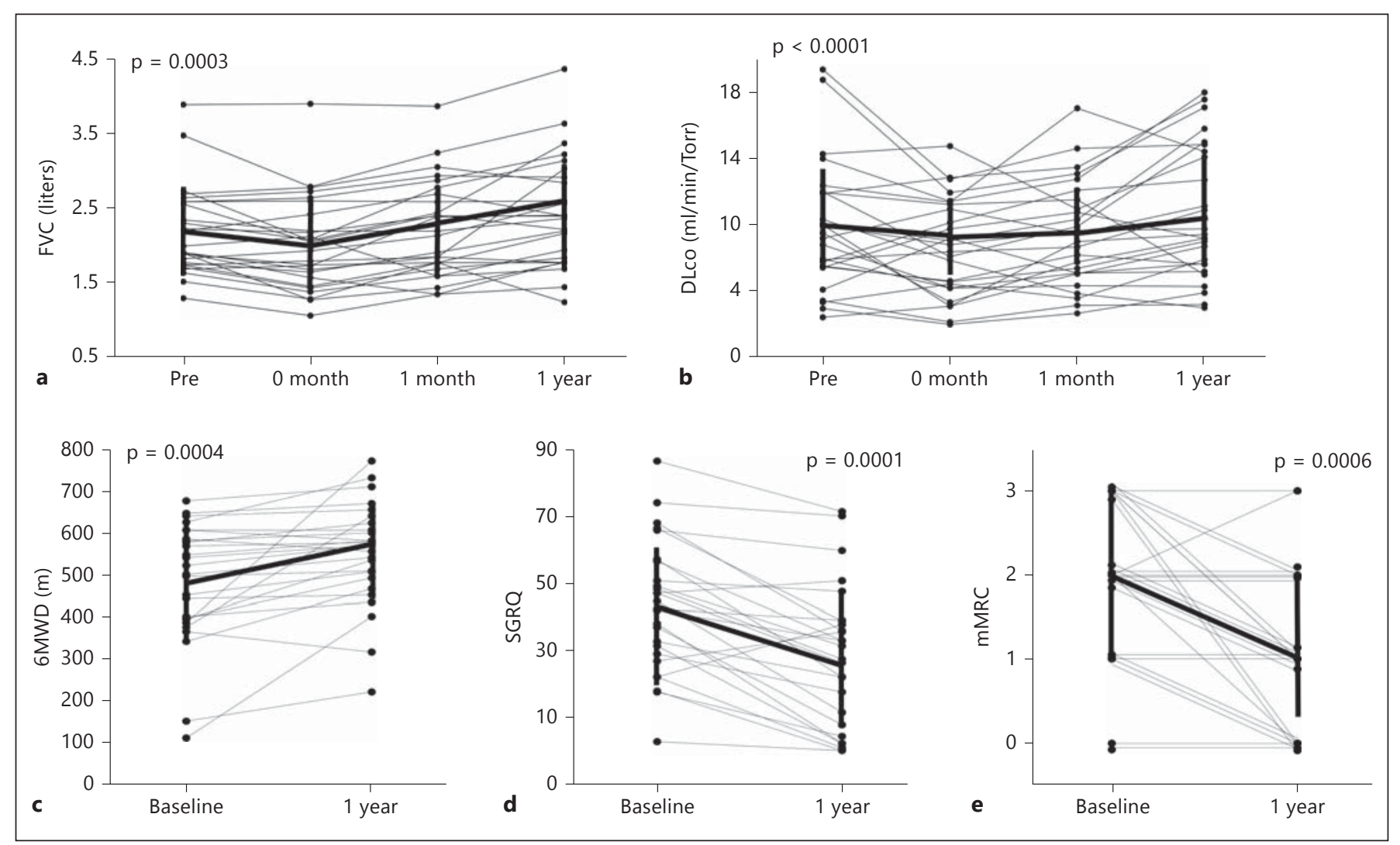

Fig. 1. Treatment effects. Improvements in FVC (a), DLco (b), 6MWD (c), SGRQ total score (d) and mMRC score (e) for each patient. Statistically significant improvements from baseline were observed in all variables at 1 year. In measurements of pulmonary function at 1 month, a statistically significant improvement was

observed in FVC compared to baseline, but not in DLco. There were significant differences in both FVC and DLco between 1 month and 1 year. In the $2-3$ months preceding 1 year of combined therapy, there was a statistically significant deterioration in both FVC and DLco.

Table 2. Changes in physiological data over time

\begin{tabular}{|c|c|c|c|}
\hline & Baseline & At 1 month & At 1 year \\
\hline \multicolumn{4}{|l|}{ Pulmonary function test } \\
\hline FVC, liters & $1.93(1.06-3.90)$ & $2.13(1.35-3.86)$ & $2.36(1.24-4.36)$ \\
\hline $\mathrm{DLco}, \mathrm{ml} / \mathrm{min} / \mathrm{mm} \mathrm{Hg}$ & $8.33(3.96-14.73)$ & $8.95(4.64-17.0)$ & $9.15(4.94-17.93)$ \\
\hline DLco, $\%$ predicted & $50.8(19.8-75.9)$ & $54.6(23.1-91.8)$ & $61.4(26.3-101.3)$ \\
\hline \multicolumn{4}{|l|}{ Dyspnea rating } \\
\hline $6 \mathrm{MWD}, \mathrm{m}$ & $500(110-675)$ & - & $570(220-770)$ \\
\hline \multicolumn{4}{|l|}{ SGRQ } \\
\hline Symptom & $42.9(4.2-95.3)$ & - & $21.9(0.0-88.3)$ \\
\hline Activity & $60.0(0.0-100.0)$ & - & $41.5(0.0-93.9)$ \\
\hline Impact & $29.0(0.0-81.2)$ & - & $17.7(0.0-69.4)$ \\
\hline
\end{tabular}

Data are shown as median (range). 


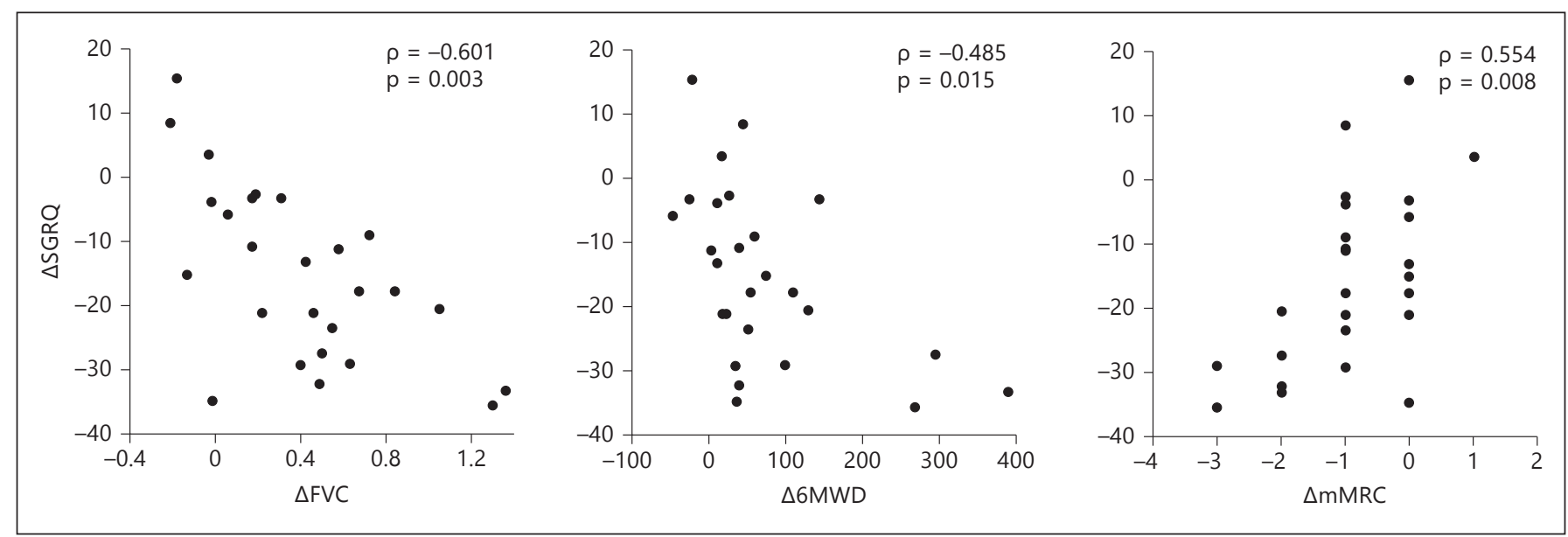

Fig. 2. Correlation between change in SGRQ and other variables at 1 year of therapy. Scatterplots of change in total SGRQ score and change in FVC, 6MWD and mMRC score. Significant correlation was observed between SGRQ total score and other variables. $\Delta$ refers to the change from the initial score.

Table 3. The proportion of patients who showed a clinically significant improvement/deterioration after 1 year of therapy among the groups of histopathological patterns

\begin{tabular}{|c|c|c|c|c|c|c|c|c|c|}
\hline & \multicolumn{3}{|l|}{ UIP } & \multicolumn{3}{|l|}{ f-NSIP } & \multicolumn{3}{|l|}{ All } \\
\hline & improved & stable & deteriorated & improved & stable & deteriorated & improved & stable & deteriorated \\
\hline FVC & $2 / 7$ & $5 / 7$ & $0 / 7$ & $14 / 19$ & $4 / 19$ & $1 / 19$ & $16 / 26$ & $9 / 26$ & $1 / 26$ \\
\hline DLco & $5 / 7$ & $2 / 7$ & $0 / 7$ & $13 / 19$ & $3 / 19$ & $3 / 19$ & $18 / 26$ & $5 / 26$ & $3 / 26$ \\
\hline 6MWD & $4 / 7$ & $2 / 7$ & $1 / 7$ & $12 / 19$ & $6 / 19$ & $1 / 19$ & $16 / 26$ & $8 / 26$ & $2 / 26$ \\
\hline SGRQ & $3 / 7$ & $3 / 7$ & $1 / 7$ & $15 / 19$ & $3 / 19$ & $1 / 19$ & $18 / 26$ & $6 / 26$ & $2 / 26$ \\
\hline
\end{tabular}

Data are shown as number of patients who showed a significant improvement or deterioration/total patients. Significant improvement/deterioration level of each variable was defined as follows: $\geqq 10 \%$ improvement/deterioration in FVC, $\geq 15 \%$ improvement/deterioration in DLco, $\geq 28 \mathrm{~m}$ improvement/deterioration in 6MWD and $\geq 7$ points decrease/increase in total score of SGRQ.

and DLco: $\mathrm{p}<0.0001)$. Both exercise capacity and total score of SGRQ showed statistically significant improvements compared with baseline values (6MWD: $481 \pm 143$ vs. $550 \pm 123 \mathrm{~m}, \mathrm{p}=0.0004$; SGRQ total score: $43.1 \pm 19.6$ vs. $27.9 \pm 21.0, \mathrm{p}=0.0001$ ). Clinically significant improvements were observed in 16 patients $(61.5 \%)$ for $6 \mathrm{MWD}$ and in $18(69.2 \%)$ for SGRQ total score. The other three components of SGRQ, i.e. symptom, activity and impact score, all improved statistically significantly compared with baseline values (symptom: $43.4 \pm 23.2$ vs. $30.5 \pm 27.3$, $\mathrm{p}=0.0149$; activity: $57.0 \pm 25.1$ vs. $39.0 \pm 27.3, \mathrm{p}=0.0003$; impact: $34.5 \pm 20.2$ vs. $21.6 \pm 19.0, p=0.0003)$. Additionally, a statistically significant improvement was observed in mMRC $(2.0 \pm 1.0$ vs. $1.1 \pm 0.9, \mathrm{p}=0.0006)$. On the other hand, clinically significant deteriorations in FVC,
DLco, 6MWD and SGRQ score were observed in 1 (3.8\%), $3(11.5 \%), 2(7.7 \%)$ and $2(7.7 \%)$ patients, respectively.

We investigated whether the magnitudes in the treatment effects depended on histopathological patterns (table 3). No significant difference was seen by pathologic pattern in the proportion of patients who showed clinically significant improvements on all measurements.

\section{Correlations between Change in SGRQ and Other \\ Variables}

To explore the possible determinants of improved HRQoL obtained from the combination therapy, we examined the correlations between change in SGRQ total score and other variables at 1 year of therapy (fig. 2). The change in SGRQ total score was significantly correlated 
Table 4. Adverse events during study period

\begin{tabular}{ll}
\hline Adverse events & $\mathrm{N}$ \\
\hline Renal dysfunction & 2 \\
Increased blood pressure & 5 \\
Infection & 5 \\
Gastrointestinal symptoms & 9 \\
Paresthesias & 4 \\
Hirsutism & 1 \\
Gingival hyperplasia & 0 \\
Diabetes mellitus & 1 \\
Swelling & 4 \\
Rash & 3 \\
\hline
\end{tabular}

with change in FVC (correlation coefficient -0.601 and $\mathrm{p}=0.003$ ), but not with change in DLco. The change in SGRQ total score also showed significant correlation with change in $6 \mathrm{MWD}$ (correlation coefficient -0.485 and $\mathrm{p}=$ 0.015 ) and change in mMRC (correlation coefficient 0.554 and $\mathrm{p}=0.008)$, respectively.

\section{Toxicity during 1 Year of Therapy}

There were no deaths during the 1 year of follow-up. Gastrointestinal symptoms (gastric pain, nausea and vomiting) were the most frequent (34.6\%) adverse effects of mild intensity (table 4 ). Two patients (7.7\%) had serum creatinine levels $>141 \mu \mathrm{mol} / \mathrm{l}$ and the adjustment in their CsA dose was associated with resolution. Elevated blood pressure (observed in 19.2\%) was well-controlled with antihypertensive drugs. There were five infections, which resolved with antimicrobial therapy. None of the adverse events was serious, and treatment did not have to be discontinued in any patient due to unacceptable toxicity.

\section{Long-Term Outcome}

Five (19.2\%) of the 26 patients treated with the combination therapy died during the observation period, including 2 who died of respiratory failure from progressive IP (median follow-up duration 4.4 and range 1.7-7.6 years). Three patients died from the progression of some kind of cancer: lung cancer (1), ureteral cancer (1) and carcinoma of unknown primary sites (1).

\section{Discussion}

We evaluated the therapeutic benefit and the tolerability of combined therapy with CsA and low-dose PSL for CTD-IP patients. One year of this combined therapy im- proved not only pulmonary function but also exercise capacity, HRQoL and dyspnea.

IP is characterized by a progressive decline in lung function, so impairments in physiological variables are usually the main focus of evaluation when treating CTDIP patients $[5,6]$. However, the most significant outcome of the treatment in this population is still not clear. Patient-reported outcomes including HRQoL and subjective dyspnea grading make it possible to incorporate the values and judgments of patients regarding treatment effects. In fact, Swigris et al. [33] demonstrated that dyspnea and HRQoL provide information not captured by measures of pulmonary function in CTD-IP patients. Patients with IP suffer from decreased exercise capacity and this often limits their activity. Exercise capacity is a crucial end point, the validity and responsiveness of which have been well-established in IP patients [34]. We therefore evaluated the efficacy of combined therapy with CsA and low-dose PSL for CTD-IP patients with several approaches. It is worthy of note that this combined therapy had significant beneficial effects on several clinically important outcomes as well as on pulmonary function.

As no controlled clinical trial data are available for CTD-IP other than SSc-IP, it is hard to compare our results directly with previous reports. Nevertheless, we take it that the magnitude of the treatment effects in this study was quite remarkable. For example, in the treatment effect for FVC, a clinically significant improvement was observed in $61.5 \%$ of the patients and median FVC of predicted value increased from 71.3 to $89.6 \%$ after 1 year of therapy. In patients with SSc-IP, a previous large trial with cyclophosphamide therapy indicated a statistically significant, however modest, treatment effect on changes in FVC. In that particular study, the mean FVC observed in the cyclophosphamide treatment group changed from 67.6 to $66.6 \%$ of predicted value at 12 months [4]. Another trial with SSc-IP patients designed by Hoyles et al. [5] failed to demonstrate a significant improvement in FVC in 12 months of treatment consisting of low-dose PSL and intravenous cyclophosphamide, followed by oral azathioprine. In contrast, it is notable that a clinically significant improvement in FVC ( $\geq 10 \%$ improvement $)$ was observed in all 4 SSc-IP patients in this study, albeit this is a small number. Among the patients with PM/DM-IP, a clinically significant improvement in FVC was observed in 5/7 (71.4\%). Although data were restricted to a small series, early intervention with combined therapy of PSL and CsA has been shown to be effective $[35,36]$. Considering our results and those of previous studies, this combined therapy is a potentially efficacious treatment for PM/DM-IP. 
In this study, treatment effects were evaluated at 1 month of treatment and after 1 year of combination therapy. At 1 month, a statistically significant improvement was observed in FVC compared to that at baseline. Furthermore, there were statistically significant differences in both FVC and DLco between 1 month and 1 year. These results indicate that combined therapy with CsA and low-dose PSL gradually improves pulmonary function over the course of a year rather than merely maintaining the therapeutic effects from mPSL induction therapy.

For CTD-IP patients, the impact of pathological pattern on treatment effect remains unclear. We examined whether the magnitude of the treatment effects depended on histopathological patterns. Clinically significant improvements of each variable were observed even in some CTD-associated UIP patients (the CTD type was RA in 6 of the 7 UIP patients). Significant treatment effects in CTD-associated UIP could be attributed to pathological differences, such as fewer fibroblastic foci, more germinal centers, smaller honeycomb cysts and more inflammation when compared with idiopathic UIP $[37,38]$. Regarding prognosis, Park et al. [39] reported that there was no difference between the survival of patients with CTDassociated UIP and CTD-associated NSIP, although the survival in patients with RA-associated UIP was worse than that in patients with CTD-associated NSIP or nonRA CTD-associated UIP. Whether or not this combination therapy alters the outcome of RA-associated UIP should be assessed in future study.

Our results demonstrated that this combination therapy significantly improved HRQoL. We conducted an additional analysis, assessing the relationship between changes in SGRQ and other measurements, in order to explore the determinants of improved QoL. Although a previous study evaluating drug efficacy in CTD-IP patients reported HRQoL score along with other outcome measures, the relationships between these are poorly understood [4]. In our study, CTD-IP patients were found to have impaired HRQoL at baseline, and the improvement in SGRQ was well-correlated with the improvements in FVC, 6MWD and mMRC. This may imply that improvement of HRQoL observed after the year of combination therapy was not a mere coincidental finding or extrapulmonary effect, but was achieved via the mechanism of this therapy that improved lung involvement, which led to the improvement of pulmonary function, the relief of symptoms and, finally, to better exercise tolerance.

The toxicities observed in this study were mostly mild to moderate and were manageable. We speculate that the reasons for the relatively few side effects are as follows.

Cyclosporin A and Low-Dose

Prednisolone in CTD-IP
First, the patients underwent low-dose maintenance PSL therapy. There is obviously concern about the long-term use of high-dose corticosteroid therapy because of potential side effects. Additionally, the steroid-sparing effect of CsA made it possible to reduce the dose of PSL in the maintenance phase. Secondly, we closely monitored the level of CsA in the blood in order to facilitate adjustment of the CsA dose. Careful data monitoring enabled us to prevent onset of severe side effects. Thirdly, all patients received prophylactic treatment with TMP-SMX. In a recent study, the addition of cotrimoxazole therapy to the standard treatment for fibrotic IP resulted in a reduction of side effects related to infection and a reduction in mortality [40]. Furthermore, TMP-SMX might play a role in preventing disease progression. In a trial of patients with progressive fibrotic lung disease, a significant improvement in FVC, shuttle-walking test, MRC and HRQoL were observed with TMP-SMX treatment [41]. We observed 1 year of combined therapy with low-dose PSL and CsA to be well-tolerated in our cohort; however, verification of the long-term efficacy and side effects is warranted in the future. During the observation period, 3 patients died of cancer. IP itself is considered to be one risk factor for lung carcinogenesis. Meanwhile, there is a possibility that CsA could have favored cancer progression although it had been already discontinued at the time of diagnosis of cancer in all 3 patients. It has been reported that CsA induces transforming growth factor-B production by tumor cells, which promotes cell invasiveness via a cell-autonomous mechanism that is independent of and/or complementary to the immunosuppressive effect of CsA on the host's immune system [42].

Recently, tacrolimus, another calcineurin inhibitor, has also been reported to be effective for CTD-IP. Guglielmi et al. [43] described a male patient in whom an acute respiratory distress syndrome related to NSIP, secondary to an antisynthetase syndrome, resolved under treatment with tacrolimus and a low dose of corticosteroids. In another report, Wilkes et al. [44] described a marked response to tacrolimus in patients with antisynthetase-associated interstitial lung disease. These reports further support the benefits of calcineurin inhibitors for CTD-IP, and future well-designed studies of this kind of drug for CTD-IP are warranted to determine what specific drugs should be used.

The limitations of this study are as follows. First, there might have been a selection bias because this was a small retrospective study that lacked a control group. However, recruitment of sufficient numbers of patients for clinical trials of CTD-IP is difficult because of the rarity of this 
condition. Second, our study population was restricted to patients who had undergone surgical lung biopsy, which may limit its generalizability. Whether physicians should make management decisions for CTD-IP without taking into account the specific histopathological pattern of IP remains unclear at present. Therefore, in order to examine whether the magnitude of the treatment effects depended on histopathological patterns, we limited our subjects to patients who had undergone surgical lung biopsy.

In conclusion, we found that 1 year of combined therapy with CsA and low-dose PSL for CTD-IP patients resulted in statistically significant improvements in a vari- ety of measurements, and the treatment effect was associated with good drug tolerance. Based on the results of this study, we believe this combined therapy is promising for CTD-IP patients. Further well-controlled studies are warranted to confirm our findings, and to evaluate longer-term outcomes and safety concerns.

\section{Acknowledgements}

This work was supported in part by a grant-in-aid for interstitial lung diseases from the Japanese Ministry of Health, Labor and Welfare and the NPO Respiratory Disease Conference.

\section{References}

1 Navaratnam V, Ali N, Smith CJ, McKeever T, Fogarty A, Hubbard RB: Does the presence of connective tissue disease modify survival in patients with pulmonary fibrosis? Respir Med 2011;105:1925-1930.

2 Pernot J, Puzenat E, Magy-Bertrand N, Manzoni P, Gondouin A, Bourdin H, SimonRigaud ML, Regnard J, Degano B: Detection of interstitial lung disease in systemic sclerosis through partitioning of lung transfer for carbon monoxide. Respiration 2012;84:461-468.

- 3 Fischer A, du Bois R: Interstitial lung disease in connective tissue disorders. Lancet 2012; 380:689-698.

4 Tashkin DP, Elashoff R, Clements PJ, Goldin J, Roth MD, Furst DE, Arriola E, Silver R, Strange C, Bolster M, Seibold JR, Riley DJ, Hsu VM, Varga J, Schraufnagel DE, Theodore A, Simms R, Wise R, Wigley F, White B, Steen V, Read C, Mayes M, Parsley E, Mubarak K, Connolly MK, Golden J, Olman M, Fessler B, Rothfield N, Metersky M; Scleroderma Lung Study Research Group: Cyclophosphamide versus placebo in scleroderma lung disease. $\mathrm{N}$ Engl J Med 2006;354:2655-2666.

5 Hoyles RK, Ellis RW, Wellsbury J, Lees B, Newlands P, Goh NS, Roberts C, Desai S, Herrick AL, McHugh NJ, Foley NM, Pearson SB, Emery P, Veale DJ, Denton CP, Wells AU, Black CM, du Bois RM: A multicenter, prospective, randomized, double-blind, placebocontrolled trial of corticosteroids and intravenous cyclophosphamide followed by oral azathioprine for the treatment of pulmonary fibrosis in scleroderma. Arthritis Rheum 2006;54:3962-3970.

-6 Kotani T, Makino S, Takeuchi T, Kagitani M, Shoda T, Hata A, Tabushi Y, Hanafusa T: Early intervention with corticosteroids and cyclosporin A and 2-hour postdose blood concentration monitoring improves the prognosis of acute/subacute interstitial pneumonia in dermatomyositis. J Rheumatol 2008;35:254-259.

-7 Puttick MP, Klinkhoff AV, Chalmers A, Ostrow DN: Treatment of progressive rheuma- toid interstitial lung disease with cyclosporine. J Rheumatol 1995;22:2163-2165.

-8 Gisslinger H, Burghuber OC, Stacher G, Schwarz W, Punzengruber C, Graninger W, Luger TA, Wolff K, Smolen JS: Efficacy of cyclosporin A in systemic sclerosis. Clin Exp Rheumatol 1991;9:383-390.

-9 Ogasawara H, Sekiya M, Murashima A, Hishikawa T, Tokano Y, Sekigawa I, Iida N, Hashimoto H, Hirose S: Very low-dose cyclosporin treatment of steroid-resistant interstitial pneumonitis associated with Sjögren's syndrome. Clin Rheumatol 1998;17:160-162.

10 Antoniou KM, Margaritopoulos G, Economidou F, Siafakas NM: Pivotal clinical dilemmas in collagen vascular diseases associated with interstitial lung involvement. Eur Respir J 2009:33:882-896.

11 Turesson C, Matteson EL, Colby TV, VukPavlovic Z, Vassallo R, Weyand CM, Tazelaar HD, Limper AH: Increased CD4+ T cell infiltrates in rheumatoid arthritis-associated interstitial pneumonitis compared with idiopathic interstitial pneumonitis. Arthritis Rheum 2005;52:73-79.

12 Kurasawa K, Nawata Y, Takabayashi K, Kumano K, Kita Y, Takiguchi Y, Kuriyama T, Sueishi M, Saito Y, Iwamoto I: Activation of pulmonary $\mathrm{T}$ cells in corticosteroid-resistant and -sensitive interstitial pneumonitis in dermatomyositis/polymyositis. Clin Exp Immunol 2002;129:541-548.

13 Bresser P, Jansen HM, Weller FR, Lutter R, Out TA: T-cell activation in the lungs of patients with systemic sclerosis and its relation with pulmonary fibrosis. Chest 2001;120: 66S-68S.

14 Tsujimura S, Saito K, Nakayamada S, Nakano $\mathrm{K}$, Tanaka Y: Clinical relevance of the expression of P-glycoprotein on peripheral blood lymphocytes to steroid resistance in patients with systemic lupus erythematosus. Arthritis Rheum 2005;52:1676-1683.

15 Idiopathic Pulmonary Fibrosis Clinical Research Network, Raghu G, Anstrom KJ, King
TE Jr, Lasky JA, Martinez FJ: Prednisone, azathioprine, and $\mathrm{N}$-acetylcysteine for pulmonary fibrosis. N Engl J Med 2012;366:19681977.

16 Richeldi L, Costabel U, Selman M, Kim DS, Hansell DM, Nicholson AG, Brown KK, Flaherty KR, Noble PW, Raghu G, Brun M, Gupta A, Juhel N, Klüglich M, du Bois RM: Efficacy of a tyrosine kinase inhibitor in idiopathic pulmonary fibrosis. N Engl J Med 2011;365: 1079-1087.

17 American Thoracic Society, European Respiratory Society: American Thoracic Society/ European Respiratory Society International Multidisciplinary Consensus Classification of the Idiopathic Interstitial Pneumonias. Am J Respir Crit Care Med 2002;165:277-304.

-18 Arnett FC, Edworthy SM, Bloch DA, McShane DJ, Fries JF, Cooper NS, Healey LA, Kaplan SR, Liang MH, Luthra HS, et al: The American Rheumatism Association 1987 revised criteria for the classification of rheumatoid arthritis. Arthritis Rheum 1988;31:315324.

19 Subcommittee for scleroderma criteria of the American Rheumatism Association Diagnostic and Therapeutic Criteria Committee. Preliminary criteria for the classification of systemic sclerosis (scleroderma). Arthritis Rheum 1980;23:581-590.

20 Bohan A, Peter JB: Polymyositis and dermatomyositis (second of two parts). N Engl J Med 1975;292:403-407.

21 Vitali C, Bombardieri S, Moutsopoulos HM, Balestrieri G, Bencivelli W, Bernstein RM, Bjerrum KB, Braga S, Coll J, de Vita S, et al: Preliminary criteria for the classification of Sjögren's syndrome. Results of a prospective concerted action supported by the European Community. Arthritis Rheum 1993;36:340347.

22 Alarcón-Segovia D, Cardiel MH: Comparison between 3 diagnostic criteria for mixed connective tissue disease. Study of 593 patients. J Rheumatol 1989;16:328-334. 
-23 Kondoh Y, Taniguchi H, Yokoi T, Nishiyama O, Ohishi T, Kato T, Suzuki K, Suzuki R: Cyclophosphamide and low-dose prednisolone in idiopathic pulmonary fibrosis and fibrosing nonspecific interstitial pneumonia. Eur Respir J 2005;25:528-533.

24 Miller MR, Hankinson J, Brusasco V, Burgos F, Casaburi R, Coates A, Crapo R, Enright P, van der Grinten CP, Gustafsson P, Jensen R, Johnson DC, MacIntyre N, McKay R, Navajas D, Pedersen OF, Pellegrino R, Viegi G, Wanger J: Standardisation of spirometry. Eur Respir J 2005;26:319-338.

25 Macintyre N, Crapo RO, Viegi G, Johnson DC, van der Grinten CP, Brusasco V, Burgos F, Casaburi R, Coates A, Enright P, Gustafsson P, Hankinson J, Jensen R, McKay R, Miller MR, Navajas D, Pedersen OF, Pellegrino R, Wanger J: Standardisation of the singlebreath determination of carbon monoxide uptake in the lung. Eur Respir J 2005;26:720735.

26 American Thoracic Society: ATS statement: guidelines for the six-minute walk test. Am J Respir Crit Care Med 2002;166:111-117.

27 Jones PW, Quirk FH, Baveystock CM, Littlejohns P: A self-complete measure of health status for chronic airflow limitation. The St. George's Respiratory Questionnaire. Am Rev Respir Dis 1992;145:1321-1327.

-28 Mahler DA, Wells CK: Evaluation of clinical methods for rating dyspnea. Chest 1988;93: 580-586.

29 American Thoracic Society: Idiopathic pulmonary fibrosis: diagnosis and treatment. International consensus statement. American Thoracic Society (ATS), and the European Respiratory Society (ERS). Am J Respir Crit Care Med 2000;161:646-664.
30 Swigris JJ, Wamboldt FS, Behr J, du Bois RM, King TE, Raghu G, Brown KK: The 6 minute walk in idiopathic pulmonary fibrosis: longitudinal changes and minimum important difference. Thorax 2010;65:173-177.

- 31 Swigris JJ, Brown KK, Behr J, du Bois RM, King TE, Raghu G, Wamboldt FS: The SF-36 and SGRQ: validity and first look at minimum important differences in IPF. Respir Med 2010;104:296-304.

-32 Wiesner RH, Ludwig J, Lindor KD, Jorgensen RA, Baldus WP, Homburger HA, Dickson ER: A controlled trial of cyclosporine in the treatment of primary biliary cirrhosis. $\mathrm{N}$ Engl J Med 1990;322:1419-1424.

33 Swigris JJ, Yorke J, Sprunger DB, Swearingen C, Pincus T, du Bois RM, Brown KK, Fischer A: Assessing dyspnea and its impact on patients with connective tissue disease-related interstitial lung disease. Respir Med 2010;104: 1350-1355.

-34 Albera C: Challenges in idiopathic pulmonary fibrosis trials: the point on end-points. Eur Respir Rev 2011;20:195-200.

- 35 Fujisawa T, Suda T, Nakamura Y, Enomoto $\mathrm{N}$, Ide K, Toyoshima M, Uchiyama H, Tamura R, Ida M, Yagi T, Yasuda K, Genma H, Hayakawa H, Chida K, Nakamura H: Differences in clinical features and prognosis of interstitial lung diseases between polymyositis and dermatomyositis. J Rheumatol 2005;32:5864.

-36 Kotani T, Takeuchi T, Makino S, Hata K, Yoshida S, Nagai K, Wakura D, Shoda T, Hanafusa $\mathrm{T}$ : Combination with corticosteroids and cyclosporin-A improves pulmonary function test results and chest HRCT findings in dermatomyositis patients with acute/subacute interstitial pneumonia. Clin Rheumatol 2011; 30:1021-1028.

-37 Song JW, Do KH, Kim MY, Jang SJ, Colby TV, Kim DS: Pathologic and radiologic differences between idiopathic and collagen vascular disease-related usual interstitial pneumonia. Chest 2009;136:23-30.
8 Flaherty KR, Colby TV, Travis WD, Toews GB, Mumford J, Murray S, Thannickal VJ, Kazerooni EA, Gross BH, Lynch JP 3rd, Martinez FJ: Fibroblastic foci in usual interstitial pneumonia: idiopathic versus collagen vascular disease. Am J Respir Crit Care Med 2003; 167:1410-1415.

39 Park JH, Kim DS, Park IN, Jang SJ, Kitaichi $\mathrm{M}$, Nicholson AG, Colby TV: Prognosis of fibrotic interstitial pneumonia: idiopathic versus collagen vascular disease-related subtypes. Am J Respir Crit Care Med 2007;175: 705-711.

40 Shulgina L, Cahn AP, Chilvers ER, Parfrey H, Clark AB, Wilson EC, Twentyman OP, Davison AG, Curtin JJ, Crawford MB, Wilson AM: Treating idiopathic pulmonary fibrosis with the addition of co-trimoxazole: a randomised controlled trial. Thorax 2013;68:155-162.

-41 Varney VA, Parnell HM, Salisbury DT, Ratnatheepan S, Tayar RB: A double blind randomised placebo controlled pilot study of oral co-trimoxazole in advanced fibrotic lung disease. Pulm Pharmacol Ther 2008;21:178187.

42 Hojo M, Morimoto T, Maluccio M, Asano T, Morimoto K, Lagman M, Shimbo T, Suthanthiran M: Cyclosporine induces cancer progression by a cell-autonomous mechanism. Nature 1999;397:530-534.

43 Guglielmi S, Merz TM, Gugger M, Suter C, Nicod LP: Acute respiratory distress syndrome secondary to antisynthetase syndrome is reversible with tacrolimus. Eur Respir J 2008;31:213-217.

44 Wilkes MR, Sereika SM, Fertig N, Lucas MR, Oddis CV: Treatment of antisynthetase-associated interstitial lung disease with tacrolimus. Arthritis Rheum 2005;52:2439-2446. 